\title{
Comparative effects of capsaicin in chronic obstructive pulmonary disease and asthma (Review)
}

\author{
MIHAI-DANIEL DUMITRACHE ${ }^{1}$, ANA STEFANIA JIEANU ${ }^{2}$, CRISTIAN SCHEAU ${ }^{2}$, IOANA ANCA BADARAU ${ }^{2}$, \\ GEORGE DENIS ALEXANDRU POPESCU ${ }^{3}$, ANA CARUNTU ${ }^{4,5}$, DANIEL OCTAVIAN COSTACHE ${ }^{6}$, \\ RALUCA SIMONA COSTACHE ${ }^{7,8}$, CAROLINA CONSTANTIN ${ }^{9,10}$, \\ MONICA NEAGU ${ }^{9-11}$ and CONSTANTIN CARUNTU ${ }^{2,12}$
}

\author{
${ }^{1}$ Department of Pneumology IV, 'Marius Nasta' Institute of Pneumophtysiology, 050159 Bucharest; \\ ${ }^{2}$ Department of Physiology, 'Carol Davila' University of Medicine and Pharmacy, 050474 Bucharest; \\ ${ }^{3}$ Department of Medical Oncology II, 'Prof. Dr. Alexandru Trestioreanu' Institute of Oncology, 022328 Bucharest; \\ ${ }^{4}$ Department of Oral and Maxillofacial Surgery, 'Dr. Carol Davila' Central Military Emergency Hospital, 010825 Bucharest; \\ ${ }^{5}$ Department of Oral and Maxillofacial Surgery, Faculty of Dental Medicine, 'Titu Maiorescu' University, 031593 Bucharest; \\ ${ }^{6}$ Department of Dermatology, 'Dr. Carol Davila' Central Military Emergency Hospital, 010825 Bucharest; \\ ${ }^{7}$ Department of Gastroenterology, Gastroenterology and Internal Medicine Clinic, 'Dr. Carol Davila' Central Military \\ Emergency Hospital, 010825 Bucharest; ${ }^{8}$ Department of Internal Medicine and Gastroenterology, \\ 'Carol Davila' University of Medicine and Pharmacy, 050474 Bucharest; ${ }^{9}$ Department of Immunology, \\ 'Victor Babes' National Institute of Pathology, 050096 Bucharest; ${ }^{10}$ Department of Pathology, \\ 'Colentina' University Hospital, 020125 Bucharest; ${ }^{11}$ Department of Biochemistry and Molecular Biology, \\ Faculty of Biology, University of Bucharest, 76201 Bucharest; ${ }^{12}$ Department of Dermatology, \\ 'Prof. N.C. Paulescu' National Institute of Diabetes, Nutrition and Metabolic Diseases, 011233 Bucharest, Romania
}

Received April 14, 2021; Accepted May 14, 2021

DOI: $10.3892 /$ etm.2021.10349

\begin{abstract}
Chronic obstructive pulmonary disease (COPD) and asthma are chronic respiratory diseases with high prevalence and mortality that significantly alter the quality of life in affected patients. While the cellular and molecular mechanisms engaged in the development and evolution of these two conditions are different, COPD and asthma share a wide array of symptoms and clinical signs that may impede differential diagnosis. However, the distinct signaling pathways regulating cough and airway hyperresponsiveness employ the interaction of different cells, molecules, and receptors. Transient receptor potential cation channel subfamily V member 1 (TRPV1) plays a major role in cough and airway inflammation. Consequently, its agonist, capsaicin, is of substantial interest in exploring the cellular effects and regulatory pathways that mediate these respiratory conditions. Increasingly more studies emphasize
\end{abstract}

Correspondence to: Dr Cristian Scheau, Department of Physiology, 'Carol Davila' University of Medicine and Pharmacy, 8 Eroii Sanitari Boulevard, 050474 Bucharest, Romania

E-mail: cristian.scheau@umfcd.ro

Key words: capsaicin, chronic obstructive pulmonary disease, asthma, cough, signaling pathways, inflammation, transient receptor potential cation channel subfamily V member 1 the use of capsaicin for the inhalation cough challenge, yet the involvement of TRPV1 in cough, bronchoconstriction, and the initiation of inflammation has not been entirely revealed. This review outlines a comparative perspective on the effects of capsaicin and its receptor in the pathophysiology of COPD and asthma, underlying the complex entanglement of molecular signals that bridge the alteration of cellular function with the multitude of clinical effects.

\section{Contents}

1. Introduction

2. Capsaicin and its receptor in the pulmonary system

3. Capsaicin in chronic obstructive pulmonary disease

4. Capsaicin in asthma

5. Conclusions

\section{Introduction}

Chronic obstructive pulmonary disease (COPD) and asthma are two common respiratory diseases with distinct pathophysiology that share some clinical features such as cough, shortness of breath, and wheezing, making differential diagnosis an essential step in their management (1-3). Despite great progress in understanding the molecular mechanisms governing the development and evolution of these conditions, 
there is still room for improvement in setting an early diagnosis and providing effective therapy.

COPD is one of the most common causes of death, an important chronic morbidity, and is characterized by persistent respiratory symptoms and airflow limitation due to anomalies of the airways and/or alveolae caused by exposure to toxic particles or gases (1). Asthma is a treatable and common disease that causes symptoms such as shortness of breath, chest tightness, and wheezing (2). Even though the two diseases are characterized by an obstructive syndrome, there are many differences between the two entities, the most representative consisting of the fact that COPD has less variability and is never completely cured, while asthma shows reversibility. Some patients may be affected by both diseases simultaneously (3). The comparative pathogenesis of COPD and asthma is shown in Fig. 1.

Capsaicin, the most pungent substance in chilli peppers, is an intensely studied molecule, with many applications in various diseases due to its anti-inflammatory and antitumoral properties (4-7). In the pulmonary system, capsaicin is used as an index of bronchial hypersensitivity, being able to produce cough and sustained bronchoconstriction, in a dose-dependent manner when inhaled (8-10). Transient receptor potential cation channel subfamily V member 1 (TRPV1) is the receptor for capsaicin in the human body. Capsaicin cough challenge shows a good correlation with the presence or absence of pathological cough (11). Capsaicin is used in many studies as a chemical agent in the diagnosis or treatment of various disorders, including respiratory conditions (12-15). A better understanding of the effects of capsaicin in COPD and asthma may reveal new ways to diagnose and differentiate these diseases and potentially new directions of treatment.

\section{Capsaicin and its receptor in the pulmonary system}

Intensely studied in various conditions and on different experimental models, in the respiratory system, capsaicin has demonstrated great pleomorphism in its actions and is closely involved in triggering an abundance of signaling pathways, at times showing converse effects in pathological situations (16). Prolonged exposure to capsaicin aerosols such as those dispersed for crowd control may be toxic, irritating the respiratory tract and causing nerve damage $(17,18)$. In extreme doses and under certain conditions, capsaicin may cause significant respiratory symptoms such as sneezing, cough, excessive mucus secretion, pain, and severe complications, and was demonstrated to be lethal in certain concentrations on test animals $(18,19)$. Moreover, in murine models, it was shown that the intravenous administration of capsaicin instantly induces apnea, followed by an increase in the respiratory rate (20). These acute effects could be reduced by vagotomy, but not in all situations $(20,21)$. However, in a clinical setting, when studying the beneficial effects of capsaicin in respiratory conditions, the doses of inhaled capsaicin are far too low to trigger significant adverse effects (22-24).

While capable of inducing direct effects, most of capsaicin's actions are mediated through its receptor, TRPV1. TRPV1 is a non-selective receptor that structurally belongs to the TRP family of ion channels. Besides capsaicin, it may be activated by different factors such as high temperature, acidity ( $\mathrm{pH}<6.0$ ), endocannabinoids, endogenous lipids, and other potential activators, such as numerous mediators of inflammation or various neurotransmitters $(25,26)$. The receptor activation sends impulses to the spinal cord and brain producing a variety of effects, such as sensations of burning, stinging, itching, warming, or tingling. The terminations of the capsaicin-sensitive nerves include numerous neuropeptides, for example, substance P (SP) or calcitonin gene-related peptide (CGRP). Their activation is followed by a temporary inflammatory process known as neurogenic inflammation because of the local release of pro-inflammatory peptides (27-30). Even though the number of TRPV1 receptors in the respiratory tract is not as high as in the other regions of the body (31), they can be found in all organs and structures of the respiratory system (32). Various pathogenic processes may influence the distribution of receptors, as was revealed in patients with emphysema which show higher levels of TRPV1 receptors in the respiratory system compared with healthy subjects $(33,34)$. TRPV1 receptors are mainly expressed in lung C-fiber afferents (35) generally recognized as fibers with polymodal sensitivity, which originate from nociceptive neurons (36). Most C-fibers are receptive to capsaicin, which acts as an important respiratory irritant (37). TRPV1 was also identified in bronchial epithelial cells (28). Alongside TRPV1, the Transient Receptor Potential Ankyrin 1 (TRPA1) receptor was revealed as being co-expressed in the airways in a population of C-fibers, and it was shown to be permeable to calcium ions (38). Although not directly stimulated by capsaicin, TRPA1 may be activated by various natural products (39), but also may be sensitized through inflammatory signaling pathways that also involve TRPV1, potentially contributing to increased chemical sensitivity $(38,40,41)$.

TRPV1 may be activated by various ligands, including derivates of ployunsaturated fatty acids, oxytocin, neurotransmitters, chalcone derivatives, and cannabinoids (42-46). Cannabinoids are of particular interest, as they have demonstrated some similarities to capsaicin in regard to their anti-inflammatory and anti-tumoral effects in various organs, albeit some of these are mediated by specific receptors (47). Cannabinoids are not able to induce similar channel states as capsaicin on TRPV1 but they manage to target the receptor and can interact with other receptors from the TRP family, as well, which emphasises the potential interaction and synergic effects of these substances (48). Cannabinoids exert a series of TRPV1 effects and the modulation of the endocannabinoid system has proven extremely important in managing a variety of disorders affecting the central nervous system as well as conditions with intestinal, pulmonary, and cutaneous locations, a virtual structure termed 'gut-lung-skin axis' (49-52).

The activation of TRPV1 has demonstrated a variety of effects (53). Several studies have shown that TRPV1 agonists may cause apoptosis of human lung cells in alveolar epithelial cells $(54,55)$. The inhalation of capsaicinoids for $30 \mathrm{~min}$ in rats causes an inflammatory reaction of the airways, destruction of epithelial cells of the trachea and nasal cavity, and injury to the bronchiolar and alveolar cells (54). Furthermore, an in vivo murine study has shown that a TRPV1 antagonism reduces the destruction of epithelial cells, preventing apoptosis (56). One of the frequently studied 


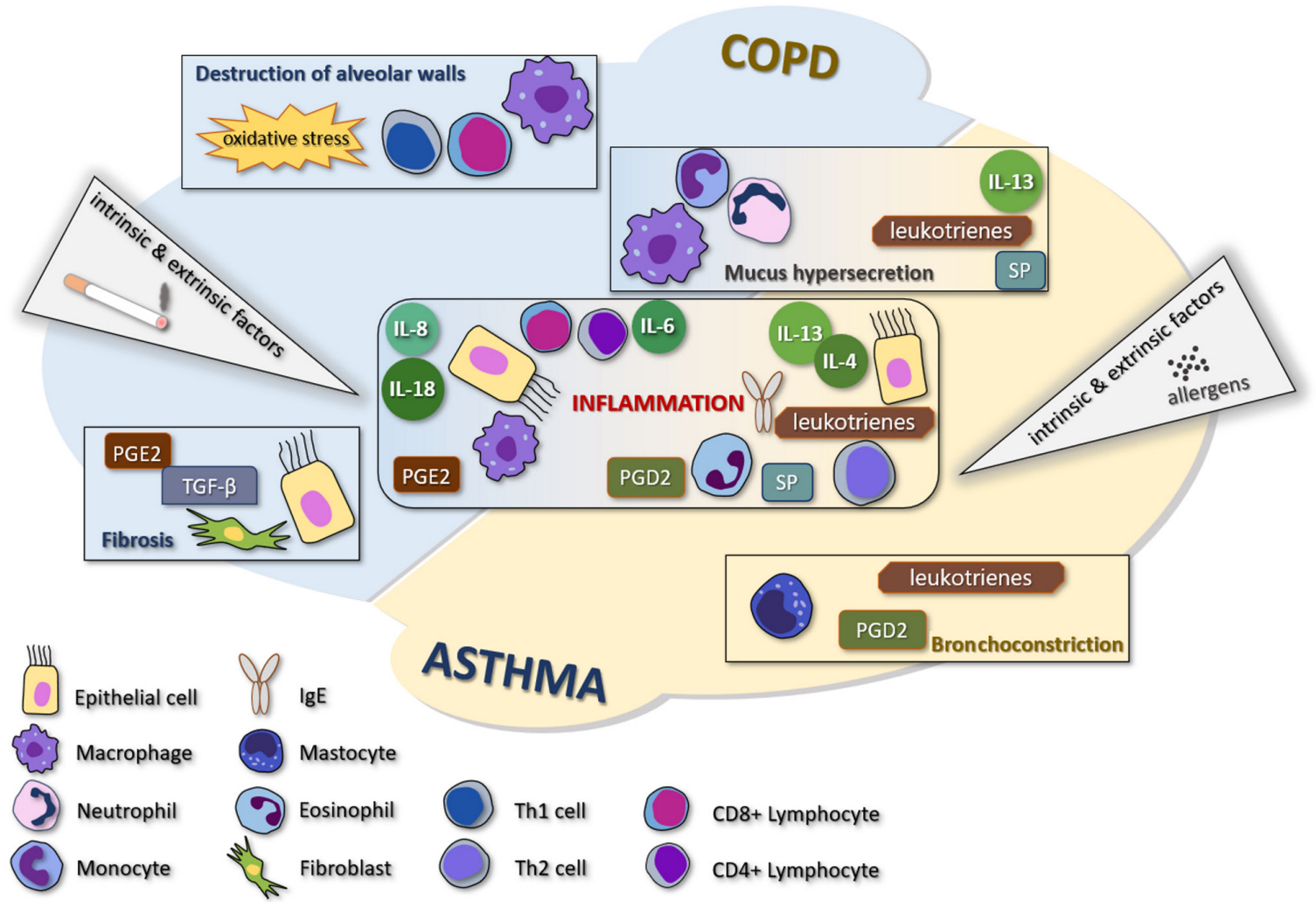

Figure 1. Comparative presentation of the most common cellular mechanisms involved in the development of the major symptoms and clinical elements of COPD and asthma. COPD, chronic obstructive pulmonary disease; TNF, tumor necrosis factor; PG, prostaglandin; SP, substance P; IL-13, interleukin-13.

TRPV1 antagonists is capsazepine. Capsazepine is a specific antagonist of capsaicin-induced $\mathrm{C}$-fiber activation and has been used to uncover additional roles of the TRPV1 receptor, specifically, its involvement in the onset of clinical respiratory symptoms (57-59).

TRPV1 may mediate cough (60) and bronchoconstriction, and the use of capsazepine reduces these symptoms in vivo (61). Furthermore, two additional TRPV1 antagonists demonstrated similar effects in inhibiting acid-induced cough in guinea pigs. These antagonists have similar effects and efficacy to that of codeine (62).

Within the respiratory system, identical signaling pathways regulate the onset of cough, bronchoconstriction, and airway narrowing, while also enhancing the sensation of irritation as well as fluid secretion. Stimulation of airway neurons may have favorable or unfavorable effects. It was reported that it might contribute to airway protection, disposing of chemical irritants and pathogens that cause infections, while preserving and initiating tissue recovery and favoring the immune responses in murine models $(63,64)$. However, the stimulation of airway neurons may cause inflammation in the respiratory airways that complicates underlying diseases, as was demonstrated on TRPV1 neurons in mouse models of asthma (65). A recent study by Baral et al indicates that pulmonary TRPV1 neurons are involved in cross-talk with immune cells via CGRP, SP, glutamate, and other signaling molecules, showing that these neurons may cause neutrophil depletion as well as cytokine and T-cell release impairment (66). These converse findings reinforce the need to further study the cascade of intricate effects triggered by TRPV1 activation and to develop novel models capable of properly translating the in vivo actions of capsaicin. In some respiratory diseases, a variety of pro-inflammatory mediators and peptides are involved, such as histamine, prostaglandins, cysteinyl leukotrienes, proteases, growth factors, and bradykinin $(64,67)$. Bradykinin is a pro-inflammatory molecule, acting through $\mathrm{B} 1$ and $\mathrm{B} 2$ receptors found in the respiratory system, which can also be involved in neuroinflammation associated with an increase in SP and CGRP (64). Bradykinin causes cough and bronchoconstriction $(67,68)$ and is involved in airway chronic inflammation, responsiveness, and remodeling through activation of a variety of cells that cause these unfavorable effects (69).

Capsaicin and the major clinical respiratory symptoms. Inhaled capsaicin is the main agent for the measurement of cough reflex sensitivity because of a lack of side effects when properly administered, low price, and good correlation with the presence or absence of pathological cough. A review from 2005 that contained 122 published studies (1984-2005) on 4.833 subjects, including healthy subjects, patients with COPD, asthma, and other diagnoses, did not manage to isolate a single serious adverse effect of inhaled capsaicin in controlled conditions when using regulated concentrations (11). The usual symptoms reported during capsaicin cough challenge are increased cough, rhinorrhea, and throat and eye irritation (70).

Asthmatics without cough could not be differentiated from healthy individuals after the capsaicin cough challenge. Moreover, it was demonstrated that hyperresponsiveness of airways and cough were mediated through different neural pathways (71). 
In vitro research using fiberoptic bronchoscopy in order to obtain mucosal biopsies from 29 patients with chronic cough showed an increase in the number of TRPV1 receptors in these subjects compared to 16 controls. Those data demonstrate a correlation between chronic cough and TRPV1 receptors. The cause of the increase was not determined. The subjects also received aerosols of a capsaicin solution dissolved in $0.9 \%$ sodium chloride until cough was produced five or more times. Results suggest an increased frequency of cough when capsaicin was inhaled by patients with chronic cough (72). In addition, cold air seems to increase the sensitivity of TRPV1 to capsaicin and increase cough sensitivity (73).

In an in vivo study on guinea pigs, the delivery of capsaicin by aerosol to the airways induced cough, while the administration of a capsaicin antagonist caused a decrease in the induced cough (74). The antagonist for capsaicin used in that study completely blocked the receptor for capsaicin and prevented its response to the variation of $\mathrm{pH}$. Additionally, it inhibited the influx of $\mathrm{Ca}^{2+}$ that blocks the effects of capsaicin. This is paramount evidence of the major role of capsaicin in cough and is an important finding for basing future human trials. In terms of the action mechanism, it appears that the effects of capsaicin were carried on by direct TRPV1 effects but also mediated by tachykinins such as SP and neurokinin A (NKA) (74).

Long-term respiratory effects after exposure to capsaicin aerosols were analyzed in several major studies. Two studies showed no difference between hot pepper workers and healthy individuals in regard to their pulmonary function $(75,76)$.

In vitro and in vivo studies suggested that capsaicin can be mutagenic; conversely, multiple studies revealed that topical, dietary, or injected capsaicin may demonstrate a chemoprotective effect (77-80).

Two decades of experience with capsaicin demonstrated that the capsaicin cough challenge is a safe investigation, and this procedure may prove to be an extremely important tool for future research.

The effects of capsaicin on mucus secretion in COPD and asthma were also investigated. In vitro, findings of several studies showed that SP stimulates mucus secretion in the respiratory system (81-83) and an increase of SP appears after stimulation of sensory nerves by capsaicin (84). In an in vivo study by Karmouty-Quintana et al increased mucus production caused by the activation of airway sensory nerves with intratracheal administered capsaicin was observed, and the results were confirmed showing a reduced level of mucin concentration after administration of capsazepine, a TRPV-1 antagonist. These effects seem to be mostly determined by SP, CGRP, and NKA released as a response to sensory nerve stimulation by capsaicin (85).

Dyspnea is a common respiratory symptom in both COPD and asthma, however, it has different attributes. In COPD, dyspnea is progressive and proportional to the airflow obstruction, while in asthma it appears simultaneously with the transitory bronchoconstriction (86). Dyspnea is a symptom that appears after the stimulation of adenosine receptors, and capsaicin shows no interference with these receptors (87). When investigated in clinical applications, no evidence that capsaicin may cause dyspnea was found, neither inhaled nor administered intravenously, in tolerable doses $(88,89)$.
Smoking is a major causative and aggravating factor in lung inflammation. However, acute and chronic infection, whether viral, bacterial, or fungal, may influence the prognosis of these patients and their response to treatment (90). Some of the infections trigger exacerbations and cause a decline in lung function, while the patient does not benefit from effective therapeutical strategies, which poses significant problems in the management of these patients (91). The lung microbiome may experience changes related to the exacerbations and may influence biomarkers such as sputum neutrophils percentage and IL-8, as well as serum IL-10 and MMP-7 (92). Capsaicin has demonstrated antimicrobial properties and may provide an added benefit in COPD patients with concurring infections, a research direction which needs to be further explored (93).

\section{Capsaicin in chronic obstructive pulmonary disease}

COPD is one of the leading causes of death and an important chronic morbidity featuring limitation of airflow, cough, mucus hypersecretion, and dyspnea. It is caused by long-term exposure to toxic particles or gases, usually tobacco smoke, and may sometimes affect patients with various genetic abnormalities or concurring respiratory diseases (94). COPD demonstrates a steady increase in mortality and morbidity and is estimated to maintain this trend (95). Besides the clinical context, spirometry is necessary for the diagnosis by confirming the airflow limitation that is established when forced expiratory volume in one second (FEV1) to forced vital capacity (FVC) ratio is under $70 \%$ of the normal limits after the use of a bronchodilator (96). In their clinical evolution, patients with COPD can have periods of time when they show no symptoms, and periods of exacerbations (1).

Capsaicin, smoking and inflammation in COPD. Inflammation is one of the fundamental characteristics of COPD. It accelerates the disease progression and it is not reversible. Inflammation in COPD is usually a consequence of smoking, which is a major factor in the pathogenesis of COPD. Most cigarette smokers have a chronic cough, which is usually present prior to the onset of airflow obstruction. Smoking induces airway inflammation causing an increase in the number of neutrophils, macrophages, and $\mathrm{T}$ lymphocytes $\left(\mathrm{CD}^{+}\right.$and $\left.\mathrm{CD}^{+}\right)(97)$. These cells release a large number of cytokines and mediators that initiate and maintain the inflammatory process (98). The mediators with increased concentrations in COPD are leukotriene B4, neutrophil and T-cell chemoattractant, chemotactic factors such as interleukin (IL)-8 and growth-related oncogene $\alpha$, pro-inflammatory cytokine (TNF)- $\alpha$, IL-1 $\beta$, IL-6), and transforming growth factor- $\beta(98,99)$. Alongside the inflammatory process, an imbalance between protease and antiprotease activity can be identified in COPD. This results from the intensified production and activity of proteases and decreased production and activity of antiprotease, caused by cigarette smoke and inflammation. Neutrophils release elastase, cathepsin G, and protease 3 , while macrophages produce cysteine protease, cathepsins E, A, L, S, and matrix metalloproteinase-8, -9 and -12 . $\alpha 1$ antitrypsin, secretory leucoprotease inhibitor, and tissue inhibitors of metalloproteases are the major antiproteases that participate in emphysema in COPD $(31,98,100)$. The alteration 
of parasympathetic afferent and efferent fibers may contribute to the onset of bronchospasm, cough, and dyspnea (101).

In vivo, in a study on mice after exposure to cigarette smoke, the levels of leukocyte infiltration and the high level of inflammatory mediators caused the progression of COPD and the decline of lung function. These processes increased the production of IL-1 $\beta$ and IL-18, two cytokines released in association with the stimulating action of TRPV1 agonists, including capsaicin, in a cell-based model using primary human cells (33). Moreover, TRPV1 is found in CD4- T cells in mice. These receptors are activated after stimulation of the T-cell antigen receptor, which contributes to the influx of $\mathrm{Ca}^{2+}$. After this influx, the $\mathrm{T}$ cells are activated playing an important role in the development of inflammation. This process indicates that TRPV1 may have a fundamental function in the inflammatory process, particularly after smoke exposure, which is the main cause of COPD (102).

Recent studies also revealed the role of TRPV1 in mediating the effects of cigarette smoke on the alveolar epithelial cells through the increase of inflammation, oxidative stress, and mitochondrial damage $(103,104)$. In patients with COPD, TRPV1 mRNA expression is increased in comparison with non-smokers (33).

The expression of TRPV1 is related to the intensity of the inflammatory process induced by cigarette smoking (105). In a mouse model, Jian et al have shown that the decreased expression of TRPV1 by using total flavonoids is followed by a subsequent decrease in the inflammation and oxidative stress in the lung parenchyma (106). A 2020 article has shown that single nucleotide polymorphisms of TRPV1 are associated with a higher risk of developing COPD in smokers (107).

In another study, human cells were exposed to cigarette smoking, and the expression of TRPV1 in pulmonary tissue was increased, as was the concentration of pro-inflammatory cytokines (108).

Stimulation of TRPV1 in COPD releases inflammatory neuropeptides which increase vascular permeability, cause extravasation of plasma proteins, bronchoconstriction, and amplify the concentration of mucus $(109,110)$. Mucus hypersecretion causes increased sputum production and seems to correlate with the severity of COPD (111).

Interestingly, in vitro studies showed that cigarette smoke can cause neuropeptide release by stimulating TRPA 1 and acetylcholine receptors, contributing to the inflammatory process, with decreased or lack of TRPV1 involvement (112). Conversely, in vivo murine models suggest that the mediation of inflammation is exclusively performed by activation TRPV1 and 4, and not by TRPA1 (33). These contradictory findings require the need for future studies, ideally on human subjects.

Capsaicin stimulates TRPV1 with further release of pro-inflammatory cytokines in the airways. Activation of TRPV1 by capsaicin in patients with COPD stimulates the secretion of ILs, TNF- $\alpha$, and prostaglandin E2 (PGE2) (113). Special attention was paid to the capsaicin-induced stimulation of IL-6 production in human respiratory epithelial cells (114). IL-6 has a very important role in the transition from acute to chronic inflammation because it stimulates T-cells and B-cells. This stimulation favors a chronic inflammatory response due to the activation of endothelial cells that release IL-8 and monocyte chemoattractant protein 1 and activate the expression of adhesion molecules (115). Nassini et al used mouse models and in vitro studies on human small airway epithelial cells, fibroblasts and smooth muscle cells exposed to cigarette smoke to demonstrate that capsaicin inhalation stimulates TRPV1 receptors in sensitive nerve fibers promoting neurogenic inflammation and favoring the release of IL-8, most likely through coactivation of TRPA1 receptors in non-neuronal cells (116). This mechanism may maintain and even increase inflammation in patients with COPD, enhancing its negative effects. Furthermore, bronchoconstriction may exacerbate the airflow limitation and intensify the dyspnea of patients.

Studying the in vivo response of the exposure of guinea pigs to cigarette smoke revealed that nebulized capsaicin enhances cough production in smoke-exposed animals, through a non-cyclo-oxygenase-mediated mechanism. The increased responsiveness to capsaicin appears to depend on sensory nerves containing CGRP-like substances (117). Moreover, while increasing sensitivity to capsaicin, exposure to smoke seems to decrease the response to PGE2, promoting the concept that sensory nerves are affected in COPD in a disease-specific manner (118).

A consensus was not yet reached regarding the overall effects of capsaicin in patients with airflow obstruction. A large cross-sectional study by Blanc et al (119) compared the effects of inhaled capsaicin on non-smokers and smokers with and without airflow obstruction. An increase of responsiveness in all groups of patients was demonstrated, more significantly in patients with COPD. Asymptomatic smokers registered no complaint, despite their hyperresponsiveness to capsaicin compared to non-smokers. In the same study, women were more sensitive than men in all three groups (119). However, no correlation was identified between the cough response intensity and the degree of airflow obstruction in COPD patients appreciated by FEV1 values, and these findings were confirmed in another study, by Doherty et al (120). Conversely, research data published in 1999 showed no significant difference in cough sensitivity to capsaicin between patients with COPD and airflow obstruction compared to healthy controls (121).

Capsaicin and cough in COPD. TRP channels have a protective role in physiological situations when the airways are not affected by pathological changes. In a disorder such as COPD, this role can be altered, and TRP channels may be responsible for the symptoms of COPD, especially cough and they may also participate in the inflammatory process identified in COPD (32).

Cough is usually the first symptom in patients with COPD. Cough may be sporadic and sometimes unproductive (1), it can affect the quality of life in patients with COPD and this is an important reason to research it and potentially identify new therapies (122). C and A fibers are expressed in the mechanism of pathological cough, so TRP ion channels are an important component of this process (38). Capsaicin is the most common and usable agonist of TRPV1, used in a variety of studies on patients with chronic cough, a category that includes patients suffering from COPD $(123,124)$.

Several clinical studies using capsaicin aerosols have been developed for patients with cough and COPD. Capsaicin responsiveness and cough in COPD was researched in a study by Doherty et al (120). The presented data suggest that inhaled 
capsaicin caused an increase in cough in patients with COPD and no relationship between cough and airflow limitation after exposure to capsaicin was observed (120). Another study, by Terada et al (125), showed an increase in the number and frequency of exacerbations after capsaicin inhalation in patients with COPD compared to controls, demonstrated by lower concentrations of capsaicin needed to produce five or more coughs; furthermore, bronchial hypersensitivity correlated with the frequency of exacerbations and the serum $\mathrm{C}$-reactive protein, indicating that ongoing airway inflammation is associated with hypersensitivity of the cough reflex to capsaicin and may precipitate the exacerbations (125). Capsaicin cough challenge may be an important aid in assessing, managing COPD and its complications, and advancing the development of a new antitussive therapy. It does not yield serious adverse effects as it was demonstrated in a paper reviewing 20 years of practicing capsaicin cough challenge (11). A cough challenge test performed on 20 patients with exacerbated COPD revealed that their sensitivity to capsaicin was increased compared to the repeated test after recovery, and if hypersensitivity was maintained during recovery this announced future exacerbations (126).

\section{Capsaicin in asthma}

Asthma is a chronic, frequent, and treatable pulmonary disease characterized by respiratory symptoms, limitation of activity, and exacerbations that occasionally need urgent medical care, and can be a potentially lethal condition. The most common respiratory symptoms in asthma are wheezing, shortness of breath, cough, chest tightness, and variable expiratory airflow. The main risk factors that may aggravate asthma are viral infections, allergens, tobacco smoke, pollens, food, drugs, or exercise. Spirometry is required to set the diagnosis: FEV1 increases by $12 \%$ and a minimum of $200 \mathrm{ml}$ of the baseline values post-bronchodilator (2).

Asthma is regarded as a typical Th2 disease, with increased immunoglobulin E (IgE) levels, airway inflammation, and the presence of numerous eosinophils. Usually, patients begin suffering from asthma in childhood. The allergens are inhaled and stimulate Th2-helper cell proliferation and the increase of IL-4, IL-5, and IL-13 levels (127). A fundamental characteristic of these patients is long-term airway inflammation. Consequently, chronicity and disease evolution disease may occur. The roles of IL-4 are to support B-cell isotype swapping, increase the response of stimulus of adhesion molecules, eotaxin creation, and improvement of airway hyperresponsiveness and goblet cell metaplasia (128-130). IL-13 partly shares its receptor with IL-4 and plays a critical role in the pathophysiology of asthma by increasing mucus secretion and modulating the functions of epithelial cells (131). Eosinophils and $\operatorname{IgE}$ are also of great importance in asthma and act via distinctive pathways which do not interfere with the mechanisms of IL-13 $(132,133)$.

TRPV1 and allergens in asthma. TRPV1 may play important roles in the modulation of the pathogenic changes occurring in asthma (105). The expression of TRPV1 and Th2 levels seems to correlate with the asthmatic debut in the pediatric population (134). Recent data showed that TRPV1 can mediate the response of epithelial cells to allergens, increasing IL-33 secretion and the activation of dual oxidase 1 and epidermal growth factor receptor (135). Furthermore, an in vivo study on mice published in 2020 has shown that TRPV1 stimulates the production of mucus and cytokines in asthma by regulating the expression of MUC5AC and nuclear factor kappa-light-chain-enhancer of activated B-cell pathway, with probable involvement of neuropeptides SP and CGRP (136). TRPV1 also mediates the appearance of cough via a neuronal mechanism and shows increased expression after exposure to allergens $(137,138)$. Although expressed on airway smooth muscle cells, TRPV1 activation does not significantly contribute to the initiation of bronchoconstriction (139). In vitro studies have shown that coal fly ash causes TRPV1 activation and worsens asthma symptom control (140). A study on ovalbumin (OVA)-induced asthmatic mice showed that exposure to nanoparticles causes neuroinflammation mediated through TRPV1 and TRPV4, and is accompanied by an increase in SP, CGRP, and bradykinin (64). A similar study showed that a pollutant known as trimellitic anhydride can increase TRPV1 expression as well as amplify the levels of IL-13, SP, prostaglandin D2, and nerve growth factor in the lungs of OVA asthmatic mice (141). In the same experimental model, Li et al identified ozone as an environmental pollutant with similar effects on TRPV1 and the inflammation pattern in asthma as the allergens mentioned above (142). Small particulate matter can also inflict bronchial mucosal damage and thickening of bronchial smooth muscles in asthmatic mice (143). Combining pollutants builds a model closer to real-life situations (144), and, by doing so on allergic Balb/c mice, activation of TRPV1 signaling and increases of CGRP and SP levels were observed contributing to the neurogenic inflammation of asthma (145). Allergen exposure may lead to pathological changes outside the respiratory tract. In an in vivo study, Spaziano et al (146) showed that sensitization of the nucleus solitary tract (NST) occurs following exposure to allergens, and this is a basis for increased airway sensitivity. When capsaicin was inhaled, an increase in the neural firings of the NST were identified. However, TRPV1 may play a complex role in modulating excitation as its activation by endocannabinoids may stimulate glutamatergic signaling and alter the bronchoconstrictive reflex (146).

These observations were demonstrated by studies on the same animal model showing that inhibition of the TRPV1 mRNA and protein expression using various antagonists including capsazepine caused an improvement in pulmonary function, decreased airway hyperresponsiveness, and reduced cytokine concentrations in aggravated asthma (145,147-149). In addition, the use of allergens to induce bronchoconstriction seems to increase the TRPV1 response to capsaicin, increasing cough reflex sensitivity, as demonstrated in a recent clinical trial (150). The effects of stimulating TRPV1 receptors with capsaicin are increased in mice with atopic dermatitis to the extent that asthmatic-like inflammation of the airways is produced while compliance of the lungs is decreased (151).

In an in vitro study, by McGarvey et al, the TRPV1 protein was found in a culture with primary bronchial epithelial cells through patch-clamp experiments. That study confirmed that capsaicin induces the release of IL-8 especially in patients with chronic airway inflammation (152). 
Capsaicin and inflammation in asthma. In asthma, chronic inflammation is one of the fundamental features of the disease. Inflammation progresses when inflammatory cells interact with local cells to create a cascade of events that triggers and maintains chronic inflammation and causes clinical symptoms. The consequences of inflammation in asthma are bronchospasm, airways mucus secretion and edema, bronchoconstriction, and bronchial epithelial damage (153).

The role of capsaicin in the process of inflammation in asthma is unclear, as some studies cite pro-inflammatory properties of capsaicin, while other recent studies revealed its anti-inflammatory effects (154).

However, TRPV1 activation seems to play an important role in the inflammatory cascade of asthma, and pharmacological inhibition of TRPV1 leads to a reduction in IgE levels as well as an attenuation of airway inflammation in mice (155).

In vitro, after using a TRPV1 antagonist, inflammation in the airway tissues of patients with chronic asthma was attenuated. These results may suggest that blocking TRPV1 may be a new direction for the anti-inflammatory treatment in asthma (156).

A study by Rehman et al showed in vivo that blocking TRPV1 in a murine model attenuates the symptomatology of asthma, probably by alleviating the inflammation of the airways. TRPV1 inhibition reduced the concentration of IL-13 and its effects on inflammation in the airways. Consequently, hyperresponsiveness and inflammation were reduced (157). Conversely, a different murine study revealed that inhibition of the TRPV1 gene may increase airway inflammation. The levels of the IgE, eosinophils, and IL-4 may be increased in the bronchoalveolar lavage fluid in this case. The authors revealed that the effects achieved by TRPV1 employ multiple mechanisms, both direct and mediated by SP, CGRP, NkA, and somatostatin (158).

Capsaicin and cough in asthma. Cough is a frequent and important symptom that influences the quality of life in patients with asthma (159) and is regulated by sensory nerves in the airways $(60,160)$. In the previously mentioned in vitro study by McGarvey et al, the expression of TRPV1 in bronchial biopsies from asthmatics refractory to corticotherapy was found to be higher than that in patients without asthma or in those with asthma that were responsive to corticoids (152). Those findings were supported by Chen et al by analyzing TRPV1 mRNA in the peripheral blood of asthmatics and concluding that TRPV1 expression levels are major factors for bronchial asthma in children (161). As mentioned before, cold air seems to increase the effects of capsaicin on TRPV1, but humified warm air has been shown to trigger cough and bronchoconstriction in mild asthmatic patients via increased activation of C-fibers (162). While spirometry is useful in investigating the response of the large airways to capsaicin, impulse oscillometry system has proven more sensitive in detecting peripheral airway function in asthmatics and the changes induced by capsaicin (163).

In a study performed in vivo on asthmatic mice with cough, the inhalation of capsaicin caused a more frequent cough and was accompanied by eosinophil infiltration detected in the bronchoalveolar lavage fluid (164). There are also data showing neutrophil infiltration in the submucosal layer in asthmatic rats after the capsaicin cough challenge, an effect of both direct
TRPV1 action as well as due to the release of neuropeptides (SP and CGRP) inducing neurogenic inflammation (165). A study on guinea pigs sensitized with capsaicin showed that the rate of coughs was notably increased, and the proposed mechanism was associated with airway tract eosinophilic inflammation (166).

Previous findings showed an increase in the frequency of cough in patients with asthma after inhalation of capsaicin. This is an effect of the hyperresponsiveness that characterizes patients with asthma. The mechanism probably involves neuronal dysfunction. When capsaicin stimulates the TRPV1 receptor, inflammatory mediators are released with further increased stimulation of the nerve fibers. This process determines membrane depolarization and release of the inflammatory mediators which are in high concentration in asthmatic patients (167). This is a possible explanation of why increased sensitivity to capsaicin has been identified as a risk factor for severe forms of asthma (168).

A study from 2019 comparing asthmatics and healthy controls showed no difference in the cough threshold after inhaled capsaicin between the two groups (163). However, in patients with asthma, the frequency of cough is higher than in healthy subjects. In addition, a higher sensitivity to capsaicin was identified in women and older patients (169). In asthmatic children, there is a decreased sensitivity to capsaicin compared to controls, which seems to be mediated by neurotransmitters released from parasympathetic neurons (170). This finding is strengthened by another recent study showing that some nervous phenotypes may induce excessive coughing in asthmatic patients due to a neuronal dysfunction $(137,171)$. Capsaicin cough challenge is more sensitive in patients with cough-variant asthma even if bronchodilators were used in these patients (120). These patients have a lower quality of life because of their frequent exposure to irritants in daily life and due to their permanent discomfort. Research data have shown a direct correlation between the quality of life and sensitivity to capsaicin, as asthmatic patients with hyperactivity to inhaled capsaicin have a significantly poorer quality of life than controls $(172,173)$.

A study published in 2020 tested the effects of inhaled capsaicin on 385 chronic cough patients, revealing that the capsaicin cough challenge is a proper method for investigating patients with variable clinical factors in asthma (174). Additionally, the test is a safe method to employ in severe asthma (175).

However, in regard to therapeutic prognostic, cough sensitivity to capsaicin may hold an important role in predicting the response to bronchial thermoplasty when used for treating patients with severe asthma (176). Alongside the different diagnostic benefits cited in asthma, capsaicin is a molecule gaining attention and is increasingly studied in animal models and human trials.

The intended finality of these findings is to improve the management of asthmatic cough. The use of the antimuscarinic bronchodilator Tiotropium has proved effective in controlling asthmatic cough in patients unresponsive to corticosteroids and long-acting $\beta 2$ agonists, and it improved capsaicin cough reflex sensitivity, leading to the conclusion that its effects are mediated through sensory nerves, rather than effective bronchoconstrictors (177). 
Table I. Comparison of capsaicin effects on cough and inflammation in COPD and asthma.

\begin{tabular}{|c|c|c|c|}
\hline Component & Effect & Study type & (Refs.) \\
\hline \multicolumn{4}{|l|}{ COPD } \\
\hline \multirow[t]{4}{*}{ Cough } & Increase in frequency & In vitro (mucosal cells) & $(60)$ \\
\hline & Increase in frequency & In vivo (guinea pigs) & $(62)$ \\
\hline & Increase in frequency & Trial & $(104,109)$ \\
\hline & Rise of exacerbation incidence & & $(109)$ \\
\hline \multirow[t]{4}{*}{ Inflammation } & Release of IL- $1 \alpha$, TNF- $\alpha$ and PGE2 & In vitro (human primary bronchial fibroblasts) & (97) \\
\hline & Release IL-8 and pro-inflammatory cytokines & In vitro (primary bronchial epithelia cells) & $(92,136)$ \\
\hline & Release IL- $1 \beta$ and IL-18 & & \\
\hline & Maintain inflammation & In vivo (mice) & $(32)$ \\
\hline \multicolumn{4}{|l|}{ Asthma } \\
\hline \multirow[t]{3}{*}{ Cough } & Increase in frequency & In vitro (bronchial cells) & $(136)$ \\
\hline & Increase in frequency & In vivo (guinea pigs) & $(149,150)$ \\
\hline & Increase in frequency & Trial & $(151,153)$ \\
\hline \multirow[t]{3}{*}{ Inflammation } & Pro-inflammatory & In vitro (bronchial cells) & $(140)$ \\
\hline & Eosinophil infiltration & In vivo (guinea pigs) & $(150)$ \\
\hline & Pro- and anti-inflammatory & In vivo (mice) & $(141,142)$ \\
\hline
\end{tabular}

COPD, chronic obstructive pulmonary disease; TNF- $\alpha$, tumor necrosis factor- $\alpha$; PG, prostaglandin; IL, interleukin.

In summary, capsaicin demonstrates complex effects on cough and inflammation in COPD and asthma, either through direct TRPV1 activity or mediated by released factors, and these findings were summarized in Table I.

\section{Conclusions}

Capsaicin may exhibit a variety of clinical and paraclinical effects in COPD and asthma. Some are similar in both diseases, while others may be significantly different or opposite. In many cited studies, the frequency and intensity of cough are increased after capsaicin inhalation in COPD, while other authors report only an increase in the frequency of cough in asthmatic patients. The effects of capsaicin on inflammation in these two diseases are different. In COPD, several studies showed that capsaicin has pro-inflammatory effects, while, in asthma, the role of capsaicin in inflammation is unclear, as various studies showed conflicting results, citing pro-inflammatory as well as anti-inflammatory effects. Most authors revealed that the hyperresponsiveness to capsaicin is higher in smokers with airflow obstruction than non-smokers and smokers without airflow obstruction. Capsaicin appears to be a safe product as we failed to identify any studies showing an increase of dyspnea in COPD or asthma after capsaicin administration, when used in tolerable doses. Capsaicin may be a very promising, cost-effective, natural, and safe tool in expediting the diagnosis of COPD and asthma in the future, with increased accuracy in selected cases, especially due to its effects on cough and inflammation.

\section{Acknowledgements}

Not applicable.

\section{Funding}

This research and APC were funded by the following grants: PN.19.29.01.01/2019, PN-III-P1-1.2-PCCDI-2017-0341 and PN-III-P1-1.2-PCCDI-2017-0782.

\section{Availability of data and materials}

Not applicable.

\section{Authors' contributions}

MDD, CS, and CCa conceived and designed the review. CS and CCa have developed the methodology and scientific approach. Preliminary documentation, data selection and analysis, writing and editing of the original draft were performed by MDD, ASJ, CS, IAB, GDAP, AC, DOC, RSC, CCo, MN, and $\mathrm{CCa}$. Content review and editing were performed by $\mathrm{CS}, \mathrm{AC}$, and $\mathrm{CCa}$. Supervision was conducted by IAB, CCo, MN, and $\mathrm{CCa}$. All authors have read and agreed to the published version of the manuscript.

\section{Ethics approval and consent to participate}

Not applicable.

\section{Patient consent for publication}

Not applicable.

\section{Competing interests}

The authors declare no conflict of interest. 


\section{References}

1. Global Initiative for Chronic Obstructive Lung Disease: Pocket Guide to COPD Diagnosis, Management and Prevention: A Guide for Health Care Professionals. Independently published, November 20, 2019.

2. Global Initiative for Asthma: Pocket Guide for Asthma Management: For Adults and Children over 5 years. Independently published, April 1, 2020.

3. Collard CD: Harrison's Pulmonary and Critical Care Medicine. Tex Heart Inst J 37: 736, 2010.

4. Popescu GD, Scheau C, Badarau IA, Dumitrache MD, Caruntu A, Scheau AE, Costache DO, Costache RS, Constantin C, Neagu M, et al: The effects of capsaicin on gastrointestinal cancers. Molecules 26: 26, 2020.

5. Scheau C, Mihai LG, Bădărău IA and Caruntu C: Emerging applications of some important natural compounds in the field of oncology. Farmacia 68: 984-991, 2020.

6. Căruntu C and Boda D: Evaluation through in vivo reflectance confocal microscopy of the cutaneous neurogenic inflammatory reaction induced by capsaicin in human subjects. J Biomed Opt 17: 085003, 2012.

7. Frydas S, Varvara G, Murmura G, Saggini A, Caraffa A, Antinolfi P, Tete' S, Tripodi D, Conti F, Cianchetti E, et al: Impact of capsaicin on mast cell inflammation. Int J Immunopathol Pharmacol 26: 597-600, 2013.

8. Fuller RW, Dixon CM and Barnes PJ: Bronchoconstrictor response to inhaled capsaicin in humans. J Appl Physiol (1985) 58: $1080-1084,1985$

9. Midgren B, Hansson L, Karlsson JA, Simonsson BG and Persson CG: Capsaicin-induced cough in humans. Am Rev Respir Dis 146: 347-351, 1992.

10. Forsberg K, Karlsson JA, Theodorsson E, Lundberg JM and Persson CG: Cough and bronchoconstriction mediated by capsaicin-sensitive sensory neurons in the guinea-pig. Pulm Pharmacol 1: 33-39, 1988

11. Dicpinigaitis PV and Alva RV: Safety of capsaicin cough challenge testing. Chest 128: 196-202, 2005.

12. Caruntu C, Negrei C, Ghita MA, Caruntu A and Ba AI: Capsaicin, a hot topic in skin pharmacology and physiology. Farmacia 63: 487-491, 2015.

13. Cavaliere C, Masieri S and Cavaliere F: Therapeutic applications of capsaicin in upper airways. Curr Drug Targets 19: 1166-1176, 2018.

14. Ternesten-Hasséus E, Johansson EL and Millqvist E: Cough reduction using capsaicin. Respir Med 109: 27-37, 2015.

15. Fattori V, Hohmann MS, Rossaneis AC, Pinho-Ribeiro FA and Verri WA: Capsaicin: Current understanding of its mechanisms and therapy of pain and other pre-clinical and clinical uses. Molecules 21: 21, 2016.

16. Ilie MA, Caruntu C, Tampa M, Georgescu SR, Matei C, Negrei C, Ion RM, Constantin C, Neagu M and Boda D: Capsaicin: Physicochemical properties, cutaneous reactions and potential applications in painful and inflammatory conditions. Exp Ther Med 18: 916-925, 2019.

17. Copeland S and Nugent K: Persistent respiratory symptoms following prolonged capsaicin exposure. Int J Occup Environ Med 4: 211-215, 2013

18. Satpute RM, Kushwaha PK, Nagar DP and Rao PV: Comparative safety evaluation of riot control agents of synthetic and natural origin. Inhal Toxicol 30: 89-97, 2018.

19. Steffee CH, Lantz PE, Flannagan LM, Thompson RL and Jason DR: Oleoresin capsicum (pepper) spray and 'in-custody deaths'. Am J Forensic Med Pathol 16: 185-192, 1995.

20. Hedner J, Hedner T and Jonason J: Capsaicin and regulation of respiration: Interaction with central substance $\mathrm{P}$ mechanisms. J Neural Transm (Vienna) 61: 239-252, 1985.

21. Kaczyńska K and Szereda-Przestaszewska M: Respiratory effects of capsaicin occur beyond the lung vagi in anaesthetized rats. Acta Neurobiol Exp (Warsz) 60: 159-165, 2000

22. Kumar P, Deb U and Kaushik MP: Evaluation of oleoresin capsicum of Capsicum frutescenes var. Nagahari containing various percentages of capsaicinoids following inhalation as an active ingredient for tear gas munitions. Inhal Toxicol 24: 659-666, 2012.

23. Dicpinigaitis PV: Review: Effect of drugs on human cough reflex sensitivity to inhaled capsaicin. Cough 8: 10,2012.

24. Costanzo MT, Yost RA and Davenport PW: Standardized method for solubility and storage of capsaicin-based solutions for cough induction. Cough 10: 6, 2014.
25. Tominaga $\mathrm{M}$ and Tominaga T: Structure and function of TRPV1. Pflugers Arch 451: 143-150, 2005.

26. Filippi A, Caruntu C, Gheorghe RO, Deftu A, Amuzescu B and Ristoiu V: Catecholamines reduce transient receptor potential vanilloid type 1 desensitization in cultured dorsal root ganglia neurons. J Physiol Pharmacol 67: 843-850, 2016.

27. Holzer P: Local effector functions of capsaicin-sensitive sensory nerve endings: Involvement of tachykinins, calcitonin gene-related peptide and other neuropeptides. Neuroscience 24: 739-768, 1988.

28. DeLoguF,Patacchini R,Fontana G and GeppettiP: TRP functions in the broncho-pulmonary system. Semin Immunopathol 38 321-329, 2016.

29. Grigore O, Mihailescu AI, Solomon I, Boda D and Caruntu C: Role of stress in modulation of skin neurogenic inflammation. Exp Ther Med 17: 997-1003, 2019.

30. Ghiţă MA, Căruntu C, Rosca AE, Căruntu A, Moraru L, Constantin C, Neagu M and Boda D: Real-time investigation of skin blood flow changes induced by topical capsaicin. Acta Dermatovenerol Croat 25: 223-227, 2017.

31. Kunert-Keil C, Bisping F, Krüger $\mathbf{J}$ and Brinkmeier $\mathrm{H}$ : Tissue-specific expression of TRP channel genes in the mouse and its variation in three different mouse strains. BMC Genomics 7: 159, 2006.

32. Grace MS, Baxter M, Dubuis E, Birrell MA and Belvisi MG Transient receptor potential (TRP) channels in the airway: Role in airway disease. Br J Pharmacol 171: 2593-2607, 2014

33. Baxter M, Eltom S, Dekkak B, Yew-Booth L, Dubuis ED, Maher SA, Belvisi MG and Birrell MA: Role of transient receptor potential and pannexin channels in cigarette smoke-triggered ATP release in the lung. Thorax 69: 1080-1089, 2014.

34. Belvisi MG and Birrell MA: The emerging role of transient receptor potential channels in chronic lung disease. Eur Respir J 50: 1601357, 2017.

35. Fisher JT: The TRPV1 ion channel: Implications for respiratory sensation and dyspnea. Respir Physiol Neurobiol 167: 45-52, 2009.

36. Gu QD, Joe DS and Gilbert CA: Activation of bitter taste receptors in pulmonary nociceptors sensitizes TRPV1 channels through the PLC and PKC signaling pathway. Am J Physiol Lung Cell Mol Physiol 312: L326-L333, 2017.

37. Alamri A, Bron R, Brock JA and Ivanusic JJ: Transient receptor potential cation channel subfamily $\mathrm{V}$ member 1 expressing corneal sensory neurons can be subdivided into at least three subpopulations. Front Neuroanat 9: 71, 2015.

38. Bessac BF and Jordt SE: Breathtaking TRP channels: TRPA1 and TRPV1 in airway chemosensation and reflex control. Physiology (Bethesda) 23: 360-370, 2008.

39. Bandell M, Story GM, Hwang SW, Viswanath V, Eid SR, Petrus MJ, Earley TJ and Patapoutian A: Noxious cold ion channel TRPA1 is activated by pungent compounds and bradykinin. Neuron 41: 849-857, 2004

40. Millqvist E, Bende M and Löwhagen O: Sensory hyperreactivity--a possible mechanism underlying cough and asthma-like symptoms. Allergy 53: 1208-1212, 1998.

41. Brooks SM: Irritant-induced chronic cough: Irritant-induced TRPpathy. Lung 186 (Suppl 1): S88-S93, 2008.

42. Benso B, Bustos D, Zarraga MO, Gonzalez W, Caballero J and Brauchi S: Chalcone derivatives as non-canonical ligands of TRPV1. Int J Biochem Cell Biol 112: 18-23, 2019.

43. Benítez-Angeles M, Morales-Lázaro SL, Juárez-González E and Rosenbaum T: TRPV1: Structure, endogenous agonists, and mechanisms. Int J Mol Sci 21: 21, 2020.

44. Szallasi A and Sheta M: Targeting TRPV1 for pain relief: Limits, losers and laurels. Expert Opin Investig Drugs 21: 1351-1369, 2012.

45. Muller C, Morales P and Reggio PH: Cannabinoid ligands targeting TRP channels. Front Mol Neurosci 11: 487, 2019.

46. Salehi B, Quispe C, Chamkhi I, El Omari N, Balahbib A, Sharifi-Rad J, Bouyahya A, Akram M, Iqbal M, Docea AO, et al: Pharmacological properties of chalcones: A review of preclinical including molecular mechanisms and clinical evidence. Front Pharmacol 11: 592654, 2021.

47. Scheau C, Badarau IA, Mihai LG, Scheau AE, Costache DO, Constantin C, Calina D, Caruntu C, Costache RS and Caruntu A: Cannabinoids in the pathophysiology of skin inflammation. Molecules 25: 25, 2020.

48. Starkus J, Jansen C, Shimoda LMN, Stokes AJ, Small-Howard AL and Turner H: Diverse TRPV1 responses to cannabinoids. Channels (Austin) 13: 172-191, 2019. 
49. Calina D, Buga AM, Mitroi M, Buha A, Caruntu C, Scheau C, Bouyahya A, El Omari N, El Menyiy N and Docea AO: The treatment of cognitive, behavioural and motor impairments from brain injury and neurodegenerative diseases through cannabinoid system modulation-evidence from in vivo studies. J Clin Med 9 9, 2020.

50. Karoly HC, Mueller RL, Bidwell LC and Hutchison KE: Cannabinoids and the microbiota-gut-brain axis: Emerging effects of cannabidiol and potential applications to alcohol use disorders. Alcohol Clin Exp Res 44: 340-353, 2020.

51. Ribeiro A, Almeida VI, Costola-de-Souza C, Ferraz-de-Paula V, Pinheiro ML, Vitoretti LB, Gimenes-Junior JA, Akamine AT, Crippa JA, Tavares-de-Lima W, et al: Cannabidiol improves lung function and inflammation in mice submitted to LPS-induced acute lung injury. Immunopharmacol Immunotoxicol 37: 35-41, 2015.

52. Cintosun A, Lara-Corrales I and Pope E: Mechanisms of cannabinoids and potential applicability to skin diseases. Clin Drug Investig 40: 293-304, 2020

53. Zholos AV: TRP channels in respiratory pathophysiology: the role of oxidative, chemical irritant and temperature stimuli. Curr Neuropharmacol 13: 279-291, 2015.

54. Reilly CA, Taylor JL, Lanza DL, Carr BA, Crouch DJ and Yost GS: Capsaicinoids cause inflammation and epithelial cell death through activation of vanilloid receptors. Toxicol Sci 73: 170-181, 2003

55. Thomas KC, Sabnis AS, Johansen ME, Lanza DL, Moos PJ, Yost GS and Reilly CA: Transient receptor potential vanilloid 1 agonists cause endoplasmic reticulum stress and cell death in human lung cells. J Pharmacol Exp Ther 321: 830-838, 2007

56. Agopyan N, Head J, Yu S and Simon SA: TRPV1 receptors mediate particulate matter-induced apoptosis. Am J Physio Lung Cell Mol Physiol 286: L563-L572, 2004.

57. Cabral LD and Giusti-Paiva A: The transient receptor potential vanilloid 1 antagonist capsazepine improves the impaired lung mechanics during endotoxemia. Basic Clin Pharmacol Toxicol 119: 421-427, 2016.

58. Tani M, Kotani S, Hayakawa C, Lin ST, Irie S, Ikeda K, Kawakami $\mathrm{K}$ and Onimaru H: Effects of a TRPV1 agonist capsaicin on respiratory rhythm generation in brainstem-spinal cord preparation from newborn rats. Pflugers Arch 469: 327-338, 2017.

59. Yang J, Yu HM, Zhou XD, Kolosov VP and Perelman JM: Study on TRPV1-mediated mechanism for the hypersecretion of mucus in respiratory inflammation. Mol Immunol 53: 161-171, 2013.

60. Bonvini SJ and Belvisi MG: Cough and airway disease: The role of ion channels. Pulm Pharmacol Ther 47: 21-28, 2017.

61. Belvisi MG, Miura M, Stretton D and Barnes PJ: Capsazepine as a selective antagonist of capsaicin-induced activation of C-fibres in guinea-pig bronchi. Eur J Pharmacol 215: 341-344, 1992

62. Leung SY, Niimi A, Williams AS, Nath P, Blanc FX, Dinh QT and Chung KF: Inhibition of citric acid- and capsaicin-induced cough by novel TRPV-1 antagonist, V112220, in guinea-pig. Cough 3: 10, 2007

63. Talbot S, Abdulnour RE, Burkett PR, Lee S, Cronin SJ Pascal MA, Laedermann C, Foster SL, Tran JV, Lai N, et al: Silencing nociceptor neurons reduces allergic airway inflammation. Neuron 87: 341-354, 2015.

64. Kim BG, Park MK, Lee PH, Lee SH, Hong J, Aung MM, Moe KT, Han NY and Jang AS: Effects of nanoparticles on neuroinflammation in a mouse model of asthma. Respir Physiol Neurobiol 271: 103292, 2020.

65. Tränkner D, Hahne N, Sugino K, Hoon MA and Zuker C: Population of sensory neurons essential for asthmatic hyperreactivity of inflamed airways. Proc Natl Acad Sci USA 111: 11515-11520, 2014.

66. Baral P, Umans BD, Li L, Wallrapp A, Bist M, Kirschbaum T, Wei Y, Zhou Y, Kuchroo VK, Burkett PR, et al: Nociceptor sensory neurons suppress neutrophil and $\gamma \delta \mathrm{T}$ cell responses in bacterial lung infections and lethal pneumonia. Nat Med 24 417-426, 2018

67. Abe K, Watanabe N, Kumagai N, Mouri T, Seki T and Yoshinaga K: Circulating kinin in patients with bronchial asthma. Experientia 23: 626-627, 1967.

68. Dolovich J, Back $\mathrm{N}$ and Arbesman CE: Kinin-like activity in nasal secretions of allergic patients. Int Arch Allergy Appl Immunol 38: 337-344, 1970.

69. Ricciardolo FLM, Folkerts G, Folino A and Mognetti B: Bradykinin in asthma: Modulation of airway inflammation and remodelling. Eur J Pharmacol 827: 181-188, 2018.
70. Ternesten-Hasséus E, Johansson K, Löwhagen O and Millqvist E: Inhalation method determines outcome of capsaicin inhalation in patients with chronic cough due to sensory hyperreactivity. Pulm Pharmacol Ther 19: 172-178, 2006.

71. Dicpinigaitis PV, Dobkin JB and Reichel J: Antitussive effect of the leukotriene receptor antagonist zafirlukast in subjects with cough-variant asthma. J Asthma 39: 291-297, 2002.

72. Groneberg DA, Niimi A, Dinh QT, Cosio B, Hew M, Fischer A and Chung KF: Increased expression of transient receptor potential vanilloid-1 in airway nerves of chronic cough. Am J Respir Crit Care Med 170: 1276-1280, 2004.

73. Millqvist E: TRP channels and temperature in airway disease-clinical significance. Temperature 2: 172-177, 2015.

74. McLeod RL, Fernandez X, Correll CC, Phelps TP, Jia Y, Wang X and Hey JA: TRPV1 antagonists attenuate antigen-provoked cough in ovalbumin sensitized guinea pigs. Cough 2: 10, 2006.

75. Blanc P, Liu D, Juarez C and Boushey HA: Cough in hot pepper workers. Chest 99: 27-32, 1991

76. Lankatilake KN and Uragoda CG: Respiratory function in chilli grinders. Occup Med (Lond) 43: 139-142, 1993.

77. Muralidhara and Narasimhamurthy K: Non-mutagenicity of capsaicin in albino mice. Food Chem Toxicol 26: 955-958, 1988.

78. Surh YJ and Lee SS: Capsaicin in hot chili pepper: Carcinogen, co-carcinogen or anticarcinogen? Food Chem Toxicol 34: 313-316, 1996.

79. Park KK and Surh YJ: Effects of capsaicin on chemically-induced two-stage mouse skin carcinogenesis. Cancer Lett 114: 183-184, 1997.

80. Georgescu SR, Sârbu MI, Matei C, Ilie MA, Caruntu C, Constantin C, Neagu M and Tampa M: Capsaicin: Friend or foe in skin cancer and other related malignancies? Nutrients 9: 1365,2017.

81. Rogers DF, Aursudkij B and Barnes PJ: Effects of tachykinins on mucus secretion in human bronchi in vitro. Eur J Pharmacol 174: 283-286, 1989

82. Meini S, Mak JCW, Rohde JAL and Rogers DF: Tachykinin control of ferret airways: Mucus secretion, bronchoconstriction and receptor mapping. Neuropeptides 24: 81-89, 1993.

83. Ramnarine SI, Hirayama Y, Barnes PJ and Rogers DF: 'Sensory-efferent' neural control of mucus secretion: Characterization using tachykinin receptor antagonists in ferret trachea in vitro. Br J Pharmacol 113: 1183-1190, 1994.

84. Szallasi A and Blumberg PM: Vanilloid (Capsaicin) receptors and mechanisms. Pharmacol Rev 51: 159-212, 1999.

85. Karmouty-Quintana H, Cannet C, Sugar R, Fozard JR, Page CP and Beckmann N: Capsaicin-induced mucus secretion in rat airways assessed in vivo and non-invasively by magnetic resonance imaging. Br J Pharmacol 150: 1022-1030, 2007.

86. O'DonnellDE, Elbehairy AF, Berton DC, Domnik NJ and Neder JA: Advances in the evaluation of respiratory pathophysiology during exercise in chronic lung diseases. Front Physiol 8: 82, 2017.

87. Smutzer G and Devassy RK: Integrating TRPV1 receptor function with capsaicin psychophysics. Adv Pharmacol Sci 2016: 1512457, 2016.

88. Burki NK and Lee LY: Mechanisms of dyspnea. Chest 138: 1196-1201, 2010

89. Winning AJ, Hamilton RD, Shea SA and Guz A: Respiratory and cardiovascular effects of central and peripheral intravenous injections of capsaicin in man: evidence for pulmonary chemosensitivity. Clin Sci (Lond) 71: 519-526, 1986.

90. Leung JM, Tiew PY, Mac Aogáin M, Budden KF, Yong VF, Thomas SS, Pethe K, Hansbro PM and Chotirmall SH: The role of acute and chronic respiratory colonization and infections in the pathogenesis of COPD. Respirology 22: 634-650, 2017.

91. Linden D, Guo-Parke H, Coyle PV, Fairley D, McAuley DF, Taggart CC and Kidney J: Respiratory viral infection: A potential "missing link" in the pathogenesis of COPD. Eur Respir Rev 28: $28,2019$.

92. Wang Z, Bafadhel M, Haldar K, Spivak A, Mayhew D, Miller BE, Tal-Singer R, Johnston SL, Ramsheh MY, Barer MR, et al: Lung microbiome dynamics in COPD exacerbations. Eur Respir J 47: 1082-1092, 2016

93. Adaszek Ł, Gadomska D, Mazurek Ł, Łyp P, Madany J and Winiarczyk S: Properties of capsaicin and its utility in veterinary and human medicine. Res Vet Sci 123: 14-19, 2019

94. Rabe KF, Hurd S, Anzueto A, Barnes PJ, Buist SA, Calverley P, Fukuchi Y, Jenkins C, Rodriguez-Roisin R, van Weel C, et al; Global Initiative for Chronic Obstructive Lung Disease: Global strategy for the diagnosis, management, and prevention of chronic obstructive pulmonary disease: GOLD executive summary. Am J Respir Crit Care Med 176: 532-555, 2007. 
95. Hillas G, Perlikos F, Tsiligianni I and Tzanakis N: Managing comorbidities in COPD. Int J Chron Obstruct Pulmon Dis 10: 95-109, 2015.

96. Eschenbacher WL: Defining Airflow Obstruction. Chronic Obstr Pulm Dis (Miami) 3: 515-518, 2016.

97. Tetley TD: Inflammatory cells and chronic obstructive pulmonary disease. Curr Drug Targets Inflamm Allergy 4: 607-618, 2005.

98. Wang Y, Xu J, Meng Y, Adcock IM and Yao X: Role of inflammatory cells in airway remodeling in COPD. Int J Chron Obstruct Pulmon Dis 13: 3341-3348, 2018.

99. Sethi S, Mahler DA, Marcus P, Owen CA, Yawn B and Rennard S: Inflammation in COPD: Implications for management. Am J Med 125: 1162-1170, 2012.

100. Barbu C, Iordache M and Man MG: Inflammation in COPD Pathogenesis, local and systemic effects. Rom J Morphol Embryol 52: 21-27, 2011

101. Audrit KJ, Delventhal L, Aydin Ö and Nassenstein C: The nervous system of airways and its remodeling in inflammatory lung diseases. Cell Tissue Res 367: 571-590, 2017.

102. Tóth BI, Benko S, Szöllosi AG, Kovács L, Rajnavölgyi E and Bíró T: Transient receptor potential vanilloid-1 signaling inhibits differentiation and activation of human dendritic cells FEBS Lett 583: 1619-1624, 2009.

103. Wang M, Zhang Y, Xu M, Zhang H, Chen Y, Chung KF, Adcock IM and Li F: Roles of TRPA1 and TRPV1 in cigarette smoke -induced airway epithelial cell injury model. Free Radic Biol Med 134: 229-238, 2019.

104. Bose P, Bathri R, Kumar L, Vijayan VK and Maudar KK: Role of oxidative stress and transient receptor potential in chronic obstructive pulmonary disease. Indian J Med Res 142: 245-260, 2015.

105. Dietrich A: Modulators of transient receptor potential (TRP) channels as therapeutic options in lung disease. Pharmaceuticals (Basel) 12: 23, 2019.

106. Jian T, Chen J, Ding X, Lv H, Li J, Wu Y, Ren B, Tong B, Zuo Y, Su K, et al: Flavonoids isolated from loquat (Eriobotrya japonica) leaves inhibit oxidative stress and inflammation induced by cigarette smoke in COPD mice: The role of TRPV1 signaling pathways. Food Funct 11: 3516-3526, 2020

107.Xiong M, Guo M, Huang D, Li J and Zhou Y: TRPV1 genetic polymorphisms and risk of COPD or COPD combined with PH in the Han Chinese population. Cell Cycle 19: 3066-3073, 2020.

108. Deering-Rice CE, Johansen ME, Roberts JK, Thomas KC Romero EG, Lee J, Yost GS, Veranth JM and Reilly CA: Transient receptor potential vanilloid-1 (TRPV1) is a mediator of lung toxicity for coal fly ash particulate material. Mol Pharmacol 81: 411-419, 2012.

109. Barnes PJ: Neurogenic inflammation in the airways. Respir Physiol 125: 145-154, 2001.

110. Wortley MA, Birrell MA and Belvisi MG: Drugs Affecting TRP Channels. Handb Exp Pharmacol 237: 213-241, 2017.

111. Tagaya E, Yagi O, Sato A, Arimura K, Takeyama K, Kondo M and Tamaoki J: Effect of tiotropium on mucus hypersecretion and airway clearance in patients with COPD. Pulm Pharmacol Ther 39: 81-84, 2016

112. Kichko TI, Kobal G and Reeh PW: Cigarette smoke has sensory effects through nicotinic and TRPA1 but not TRPV1 receptors on the isolated mouse trachea and larynx. Am J Physiol Lung Cell Mol Physiol 309: L812-L820, 2015.

113. Sadofsky LR, Ramachandran R, Crow C, Cowen M, Compton SJ and Morice AH: Inflammatory stimuli up-regulate transien receptor potential vanilloid-1 expression in human bronchial fibroblasts. Exp Lung Res 38: 75-81, 2012.

114. Seki N, Shirasaki H, Kikuchi M and Himi T: Capsaicin induces the production of IL-6 in human upper respiratory epithelial cells. Life Sci 80: 1592-1597, 2007.

115. Gabay C: Interleukin-6 and chronic inflammation. Arthritis Res Ther 8 (Suppl 2): S3, 2006

116. Nassini R, Pedretti P, Moretto N, Fusi C, Carnini C, Facchinetti F, Viscomi AR, Pisano AR, Stokesberry S, Brunmark C, et al: Transient receptor potential ankyrin 1 channel localized to non-neuronal airway cells promotes non-neurogenic inflammation. PLoS One 7: e42454, 2012.

117. KarlssonJA.ZackrissonCand Lundberg JM:Hyperresponsiveness to tussive stimuli in cigarette smoke-exposed guinea-pigs: A role for capsaicin-sensitive, calcitonin gene-related peptide-containing nerves. Acta Physiol Scand 141: 445-454, 1991.

118. Belvisi MG, Birrell MA, Khalid S, Wortley MA, Dockry R, Coote J, Holt K, Dubuis E, Kelsall A, Maher SA, et al: Neurophenotypes in airway diseases. Insights from translational cough studies. Am J Respir Crit Care Med 193: 1364-1372, 2016.
119. Blanc FX, Macedo P, Hew M and Chung KF: Capsaicin cough sensitivity in smokers with and without airflow obstruction. Respir Med 103: 786-790, 2009.

120. Doherty MJ, Mister R, Pearson MG and Calverley PM: Capsaicin responsiveness and cough in asthma and chronic obstructive pulmonary disease. Thorax 55: 643-649, 2000.

121. Wong $\mathrm{CH}$ and Morice $\mathrm{AH}$ : Cough threshold in patients with chronic obstructive pulmonary disease. Thorax 54: 62-64, 1999.

122. Deslee G, Burgel PR, Escamilla R, Chanez P, Court-Fortune I, Nesme-Meyer P, Brinchault-Rabin G, Perez T, Jebrak G, Caillaud D, et al: Impact of current cough on health-related quality of life in patients with COPD. Int J Chron Obstruct Pulmon Dis 11: 2091-2097, 2016.

123. Morice AH, Millqvist E, Bieksiene K, Birring SS, Dicpinigaitis P, Domingo Ribas C, Hilton Boon M, Kantar A, Lai K, McGarvey L, et al: ERS guidelines on the diagnosis and treatment of chronic cough in adults and children. Eur Respir J 55: 55, 2020.

124. Ternesten-Hasséus E, Larsson C, Larsson S and Millqvist E: Capsaicin sensitivity in patients with chronic cough- results from a cross-sectional study. Cough 9: 5, 2013

125. Terada K, Muro S, Ohara T, Haruna A, Marumo S, Kudo M, Ogawa E, Hoshino Y, Hirai T, Niimi A, et al: Cough-reflex sensitivity to inhaled capsaicin in COPD associated with increased exacerbation frequency. Respirology 14: 1151-1155, 2009

126. Cho PSP, Fletcher HV, Turner RD, Patel IS, Jolley CJ and Birring SS: The relationship between cough reflex sensitivity and exacerbation frequency in chronic obstructive pulmonary disease. Lung 198: 617-628, 2020.

127. Fahy JV: Type 2 inflammation in asthma - present in most, absent in many. Nat Rev Immunol 15: 57-65, 2015.

128. Mishra V, Banga J and Silveyra P: Oxidative stress and cellular pathways of asthma and inflammation: Therapeutic strategies and pharmacological targets. Pharmacol Ther 181: 169-182, 2018.

129. Vieira Braga FA, Kar G, Berg M, Carpaij OA, Polanski K, Simon LM, Brouwer S, Gomes T, Hesse L, Jiang J, et al: A cellular census of human lungs identifies novel cell states in health and in asthma. Nat Med 25: 1153-1163, 2019.

130. Danahay H, Pessotti AD, Coote J, Montgomery BE, Xia D, Wilson A, Yang H, Wang Z, Bevan L, Thomas C, et al: Notch2 is required for inflammatory cytokine-driven goblet cell metaplasia in the lung. Cell Rep 10: 239-252, 2015.

131. Gour N and Wills-Karp M: IL-4 and IL-13 signaling in allergic airway disease. Cytokine 75: 68-78, 2015.

132. Wills-Karp M, Luyimbazi J, Xu X, Schofield B, Neben TY, Karp CL and Donaldson DD: Interleukin-13: Central mediator of allergic asthma. Science 282: 2258-2261, 1998.

133. Webb DC, McKenzie AN, Koskinen AM, Yang M, Mattes J and Foster PS: Integrated signals between IL-13, IL-4, and IL-5 regulate airways hyperreactivity. J Immunol 165: 108-113, 2000

134. Ren YF, Li H, Xing XH, Guan HS, Zhang BA, Chen CL and Zhang JH: Preliminary study on pathogenesis of bronchial asthma in children. Pediatr Res 77: 506-510, 2015.

135. Schiffers C, Hristova M, Habibovic A, Dustin CM, Danyal K, Reynaert NL, Wouters EF and van der Vliet A: The transient receptor potential channel vanilloid 1 is critical in innate airway epithelial responses to protease allergens. Am J Respir Cell Mol Biol 63: 198-208, 2020

136. Jing X, Yan W, Zeng H and Cheng W: Qingfei oral liquid alleviates airway hyperresponsiveness and mucus hypersecretion via TRPV1 signaling in RSV-infected asthmatic mice. Biomed Pharmacother 128: 110340, 2020.

137. Satia I, Nagashima A and Usmani OS: Exploring the role of nerves in asthma; insights from the study of cough. Biochem Pharmacol 179: 113901, 2020

138. Zhang G, Lin R-L, Wiggers M, Snow DM and Lee L-Y: Altered expression of TRPV1 and sensitivity to capsaicin in pulmonary myelinated afferents following chronic airway inflammation in the rat. J Physiol 586: 5771-5786, 2008.

139. Yocum GT, Chen J, Choi CH, Townsend EA, Zhang Y, Xu D Fu XW, Sanderson MJ and Emala CW: Role of transient receptor potential vanilloid 1 in the modulation of airway smooth muscle tone and calcium handling. Am J Physiol Lung Cell Mol Physiol 312: L812-L821, 2017.

140. Deering-Rice CE, Stockmann C, Romero EG, Lu Z, Shapiro D, Stone BL, Fassl B, Nkoy F, Uchida DA, Ward RM, et al: Characterization of transient receptor potential vanilloid-1 (TRPV1) variant activation by coal fly ash particles and associations with altered transient receptor potential ankyrin-1 (TRPA1) expression and asthma. J Biol Chem 291: 24866-24879, 2016. 
141.Li M, Fan X, Ji L, Fan Y and Xu L: Exacerbating effects of trimellitic anhydride in ovalbumin-induced asthmatic mice and the gene and protein expressions of TRPA1, TRPV1, TRPV2 in lung tissue. Int Immunopharmacol 69: 159-168, 2019.

142. Li J, Chen Y, Chen QY, Liu D, Xu L, Cheng G, Yang X, Guo Z and Zeng Y: Role of transient receptor potential cation channel subfamily V member 1 (TRPV1) on ozone-exacerbated allergic asthma in mice. Environ Pollut 247: 586-594, 2019.

143.Liu H, Fan X, Wang N, Zhang Y and Yu J: Exacerbating effects of PM2.5 in OVA-sensitized and challenged mice and the expression of TRPA1 and TRPV1 proteins in lungs. J Asthma 54: 807-817, 2017.

144. Akopian AN, Fanick ER and Brooks EG: TRP channels and traffic-related environmental pollution-induced pulmonary disease. Semin Immunopathol 38: 331-338, 2016.

145. Song J, Kang J, Lin B, Li J, Zhu Y, Du J, Yang X, Xi Z and Li R: Mediating role of TRPV1 Ion channels in the co-exposure to PM2.5 and formaldehyde of Balb/c mice asthma model. Sci Rep 7: 11926, 2017.

146. Spaziano G, Luongo L, Guida F, Petrosino S, Matteis M, Palazzo E, Sullo N, de Novellis V, Di Marzo V, Rossi F, et al: Exposure to allergen causes changes in NTS neural activities after intratracheal capsaicin application, in endocannabinoid levels and in the GLIA morphology of NTS. BioMed Res Int 2015: 980983, 2015.

147. Wang P, Liu H, Fan X, Zhu Z and Zhu Y: Effect of San'ao decoction on aggravated asthma mice model induced by PM2.5 and TRPA1/ TRPV1 expressions. J Ethnopharmacol 236: 82-90, 2019.

148. Choi JY, Lee HY, Hur J, Kim KH, Kang JY, Rhee CK and Lee SY: TRPV1 blocking alleviates airway inflammation and remodeling in a chronic asthma murine model. Allergy Asthma Immunol Res 10: 216-224, 2018.

149. Zhao L, Zhang X, Kuang H, Wu J, Guo Y and Ma L: Effect of TRPV1 channel on the proliferation and apoptosis in asthmatic rat airway smooth muscle cells. Exp Lung Res 39: 283-294, 2013

150. Satia I, Watson R, Scime T, Dockry RJ, Sen S, Ford JW, Mitchell PD, Fowler SJ, Gauvreau GM, O'Byrne PM, et al: Allergen challenge increases capsaicin-evoked cough responses in patients with allergic asthma. J Allergy Clin Immunol 144: 788-795.e1, 2019.

151. Han RT, Kim S, Choi K, Jwa H, Lee J, Kim HY, Kim HJ, Kim HR, Back SK and Na HS: Asthma-like airway inflammation and responses in a rat model of atopic dermatitis induced by neonatal capsaicin treatment. J Asthma Allergy 10: 181-189, 2017.

152. McGarvey LP, Butler CA, Stokesberry S, Polley L, McQuaid S, Abdullah H, Ashraf S, McGahon MK, Curtis TM, Arron J, et al: Increased expression of bronchial epithelial transient receptor potential vanilloid 1 channels in patients with severe asthma. J Allergy Clin Immunol 133: 704-12.e4, 2014

153. Lemanske RF Jr: Inflammatory events in asthma: An expanding equation. J Allergy Clin Immunol 105: S633-S636, 2000.

154.Bujak JK, Kosmala D, Szopa IM, Majchrzak K and Bednarczyk P: Inflammation, cancer and immunity-implication of TRPV1 Channel. Front Oncol 9: 1087, 2019.

155. Baker K, Raemdonck K, Dekkak B, Snelgrove RJ, Ford J, Shala F, Belvisi MG and Birrell MA: Role of the ion channel, transient receptor potential cation channel subfamily $\mathrm{V}$ member 1 (TRPV1), in allergic asthma. Respir Res 17: 67, 2016.

156. Kim JH: The Emerging role of TRPV1 in airway inflammation. Allergy Asthma Immunol Res 10: 187-188, 2018

157.Rehman R, Bhat YA, Panda L and Mabalirajan U: TRPV1 inhibition attenuates IL-13 mediated asthma features in mice by reducing airway epithelial injury. Int Immunopharmacol 15 : 597-605, 2013.

158. Mori T, Saito K, Ohki Y, Arakawa H, Tominaga M and Tokuyama K: Lack of transient receptor potential vanilloid-1 enhances Th2-biased immune response of the airways in mice receiving intranasal, but not intraperitoneal, sensitization. Int Arch Allergy Immunol 156: 305-312, 2011.

159. Purokivi M, Koskela H and Kontra K: Determinants of asthma control and quality of life in stable asthma: Evaluation of two new cough provocation tests. Clin Respir J 7: 253-260, 2013.

160. Puebla-Neira D and Calhoun WJ: Why do asthma patients cough? New insights into cough in allergic asthma. J Allergy Clin Immunol 144: 656-657, 2019.
161. Chen CL, Li H, Xing XH, Guan HS, Zhang JH and Zhao JW: Effect of TRPV1 gene mutation on bronchial asthma in children before and after treatment. Allergy Asthma Proc 36: e29-e36, 2015.

162. Lin YJ, Lin RL, Khosravi M and Lee LY: Hypersensitivity of vagal pulmonary $\mathrm{C}$-fibers induced by increasing airway temperature in ovalbumin-sensitized rats. Am J Physiol Regul Integr Comp Physiol 309: R1285-R1291, 2015.

163. Johansson EL, Gustafsson P, MillqvistE and Ternesten-Hasséus E: Small and large airways' reactions to inhaled capsaicin in patients with chronic idiopathic cough, or asthma and in healthy control subjects. Exp Lung Res 45: 55-64, 2019

164. Chen L, Li C, Peng M, Xie J, Lai K and Zhong N: Establishment of a mouse model with all four clinical features of eosinophilic bronchitis. Sci Rep 10: 10557, 2020.

165. Xu X, Chen Q, Qiu Z, Shi C, Ding H, Wang L, Lv H and Yu L: Association of cough hypersensitivity with tracheal TRPV1 activation and neurogenic inflammation in a novel guinea pig model of citric acid-induced chronic cough. J Int Med Res 46: 2913-2924, 2018.

166. Liu Q, Fujimura M, Tachibana H, Myou S, Kasahara K and Yasui M: Characterization of increased cough sensitivity after antigen challenge in guinea pigs. Clin Exp Allergy 31: 474-484, 2001.

167. Satia I, Tsamandouras N, Holt K, Badri H, Woodhead M, Ogungbenro K, Felton TW, O'Byrne PM, Fowler SJ and Smith JA: Capsaicin-evoked cough responses in asthmatic patients: Evidence for airway neuronal dysfunction. J Allergy Clin Immunol 139: 771-779.e10, 2017.

168. Kanemitsu Y, Fukumitsu K, Kurokawa R, Takeda N, Suzuki M, Yap J, Nishiyama H, Tajiri T, Fukuda S, Uemura T, et al: Increased capsaicin sensitivity in patients with severe asthma is associated with worse clinical outcome. Am J Respir Crit Care Med 201: 1068-1077, 2020.

169. Lai K, Long L, Yi F, Tang J, Chen Z, Chen F, Zhou J, Peng W, Zhang L, Li H, et al: Age and sex distribution of chinese chronic cough patients and their relationship with capsaicin cough sensitivity. Allergy Asthma Immunol Res 11: 871-884, 2019.

170. Kunc P, Fabry J, Lucanska M, Zatko T, Grendar M and Pecova R: Cough reflex sensitivity in asthmatic children. Physiol Res 69 (Suppl 1): S147-S150, 2020.

171. Satia I and O'Byrne PM: Identifying a neurophenotype in severe asthma. Am J Respir Crit Care Med 201: 1024-1025, 2020

172. Nakajima T, Nishimura Y, Nishiuma T, Kotani Y, Nakata H and Yokoyama M: Cough sensitivity in pure cough variant asthma elicited using continuous capsaicin inhalation. Allergol Int 55: $149-155,2006$

173. Millqvist E, Löwhagen O and Bende M: Quality of life and capsaicin sensitivity in patients with sensory airway hyperreactivity. Allergy 55: 540-545, 2000

174. Park KH, Kim BG, Lee PH, Hong J, Lee J, Park SW, Kim DJ and Jang AS: Impact of capsaicin concentration evoking coughs on clinical variables in patients with asthma. Exp Lung Res 47: $1-8,2021$.

175. Wang R, Fowler SJ, Niven R, Ryan D, Holt K, Mitchell J, Dockry R, Al-Sheklly B, Satia I and Smith JA: Investigating the safety of capsaicin cough challenge in severe asthma. Clin Exp Allergy 49: 932-934, 2019.

176. Yamamura K, Hara J, Ohkura N, Abo M, Sone T, Kimura H and Kasahara K: Increased cough receptor sensitivity to capsaicin predicts a positive bronchial thermoplasty response: A single-center retrospective study. J Bronchology Interv Pulmonol 26: 137-141, 2019.

177. Fukumitsu K, Kanemitsu Y, Asano T, Takeda N, Ichikawa H, Yap JM, Fukuda S, Uemura T, Takakuwa O, Ohkubo $\mathrm{H}$, et al: Tiotropium attenuates refractory cough and capsaicin cough reflex sensitivity in patients with asthma. J Allergy Clin Immunol Pract 6: 1613-1620.e1612, 2018.

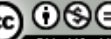

This work is licensed under a Creative Common Attribution-NonCommercial-NoDerivatives 4.0 International (CC BY-NC-ND 4.0) License. 